\title{
Evaluation of Employment Services Plus
}

\author{
Kimberly L. Gee ${ }^{1}$ \\ ${ }^{1}$ Missouri Vocational Rehabilitation \\ Keywords: specialized program, job placement, vocational rehabilitation \\ https://doi.org/10.52017/001c.26128
}

\section{Rehabilitation Counselors and Educators Journal}

Vol. 10, Issue 2, 2021

\begin{abstract}
Employment Services Plus (ESP) is a specialized employment program designed to serve individuals with autism spectrum disorder, those with traumatic brain injury, and individuals who are Deaf or hard-of-hearing served through Missouri Vocational Rehabilitation (VR). Given the additional resources needed to implement the program, the state VR program sought to learn if ESP resulted in improved employment outcomes when compared to more traditional approaches. This study investigated whether there was a difference in successful outcomes in the ESP program in Missouri when compared to the traditional Employment Services and Supported Employment service options by analyzing data on participants who exited VR between FY 2013 and FY 2019. In addition to the quantitative data analysis, a survey was used to examine the aspects of the program relevant to participants' success reported by rehabilitation professionals working within VR and the community rehabilitation agencies. Findings indicated that success was most frequently achieved by participants in Employment Services or Employment Services Plus regardless of disability type or other factors.
\end{abstract}

\section{Background and Purpose}

Employment Services Plus (ESP) is a job placement model developed by Missouri Vocational Rehabilitation (VR) in 2012, designed to serve as an alternative to the traditional Supported Employment (SE) and Employment Services (ES) job placement options. ESP was developed specifically to assist individuals with a diagnosis of autism spectrum disorder, traumatic brain injury, and/or cultural deafness/hard-of-hearing. Individuals meeting these diagnostic criteria also have barriers requiring additional disability-related service needs that exceed the level of support provided through ES, but do not meet the level of support required by participants in SE.

ESP services and supports include social skills training, employer education, environmental analysis, communication mode, processing strategies, compensatory strategies, occupational/speech/language therapy, certified Deaf interpreters, oral transliteration, video relay service, remote video interpreting, and knowledge of Deaf culture (Missouri Vocational Rehabilitation, 2021). The ESP program is available through 23 comunity rehabilitation service locations, with 16 locations providing services for autism spectrum disorder, 11 providing services for traumatic brain injury, and nine providing services for Deaf/hard-of-hearing.

The purpose of this study was to identify whether there was a difference in the successful outcome rate in Employment Services Plus programs provided by Community Rehabilitation Programs (CRP) providers in Missouri when com- pared to traditional Employment Services and Supported Employment job placement options.

\section{Methods}

This study employed a mixed method design to enhance the systematic integration of quantitative and qualitative data (Wisdom \& Creswell, 2013). Case service data was used to measure VR outcomes of the target and control groups, while a survey was conducted to collect feedback about the characteristics of the program that made ESP effective. Data from all three ESP disability-specific job placement programs were analyzed for the October 1, 2012 through September 30, 2019 period. Data included participants' age at application for VR services, gender, disability priority category, and Social Security Disability benefit status. Employment outcome status, average wages, number of hours worked, and average cost of services were also included.

Following collection of data from the AWARE case management system, a survey was developed to collect feedback about the characteristics of the program that made ESP effective. Respondents were asked to: (a) rank the most important characteristics in the selection of ESP over ES or SE job placement options; (b) indicate factors that contribute to the successful outcomes of participants (e.g., characteristics of the program, the job developer, and the vocational rehabilitation counselor); and (c) provide open-ended responses. The survey was sent to program supervisors at the 23 CRP sites offering ESP options, as well as to district su- 
Table 1. Rehabilitated Closures by Service and Disability Types

\begin{tabular}{|c|c|c|c|c|c|}
\hline & \multicolumn{2}{|c|}{ Total } & \multirow{2}{*}{$\frac{\text { SE only }(N=2,866)}{\%}$} & \multirow{2}{*}{$\frac{\text { ES only }(\mathrm{N}=1,282)}{\%}$} & \multirow{2}{*}{$\frac{\text { ESP only }(N=1,604)}{\%}$} \\
\hline & $\mathrm{n}$ & $\%$ & & & \\
\hline Autism spectrum disorder & 3,306 & 57.0 & 47.6 & 75.6 & 69.7 \\
\hline Traumatic brain injury & 1,015 & 51.9 & 35.5 & 55.9 & 66.2 \\
\hline Deaf/hard-of-hearing & 749 & 62.5 & 29.3 & 64.8 & 62.7 \\
\hline Other disabilities & 682 & 59.0 & 27.3 & 64.8 & 62.7 \\
\hline Total & 5,752 & 57.1 & 44.3 & 67.2 & 68.1 \\
\hline
\end{tabular}

Table 2. Cost of Vocational Rehabilitation Services

\begin{tabular}{|c|c|c|c|c|c|c|}
\hline & \multicolumn{2}{|c|}{$\begin{array}{c}\text { SE only } \\
(\mathrm{N}=2,866)\end{array}$} & \multicolumn{2}{|c|}{$\begin{array}{c}\text { ES only } \\
(\mathrm{N}=1,282)\end{array}$} & \multicolumn{2}{|c|}{$\begin{array}{c}\text { ESP only } \\
(\mathrm{N}=1,604)\end{array}$} \\
\hline & $\begin{array}{c}\text { No } \\
\text { employment }\end{array}$ & $\begin{array}{l}\text { Employment } \\
\text { outcome }\end{array}$ & $\begin{array}{c}\text { No } \\
\text { employment }\end{array}$ & $\begin{array}{c}\text { Employment } \\
\text { outcome }\end{array}$ & $\begin{array}{c}\text { No } \\
\text { employment }\end{array}$ & $\begin{array}{c}\text { Employment } \\
\text { outcome }\end{array}$ \\
\hline $\begin{array}{c}\text { Cost of VR } \\
\text { services }\end{array}$ & $\$ 2,143$ & $\$ 6,464$ & $\$ 2,366$ & $\$ 7,439$ & $\$ 4,258$ & $\$ 14,268$ \\
\hline
\end{tabular}

pervisors at 15 Missouri VR district offices with an ESP program in their catchment area. Supervisors were asked to complete the survey, and to forward it to their staff who worked with an ESP program.

\section{Results}

\section{Quantitative Data}

Data were analyzed for 5,752 VR participants in CRP job placement options that included ESP, ES, and SE Only. On average, $57.1 \%$ of consumers exited the agency with a successful employment outcome. When the rehabilitation rates across service delivery systems were compared, a lower rate (44.3\%) of participants in SE Only services achieved a successful employment outcome. In comparison, participants in ES Only achieved success at $67.2 \%$, while participants in ESP Only achieved success at $68.1 \%$ (see Table 1 ).

Overall, it took longer for ES (an average of 575 days) participants to exit the VR system from application than SE (444 days) and ESP (464 days) participants. Regardless of the program in which they were involved, the length of VR process was longer among those with an employment outcome (521 days) than without (460 days). However, each program showed different trends in terms of the duration of the VR process. Participants in SE appeared to take approximately five months longer to move entirely through the process from application to exit when a successful employment outcome was achieved (377 days vs. 527 days). As for ES (551 days) and ESP (447 days) participants, it took shorter time for those with an employment outcome to exit the program than those without employment (625 days and 501 days, respectively).

However, ESP services were at least twice as expensive as ES and three times as expensive as SE. When the employment outcome was controlled, ESP continued to be more expensive than all other job placement service options, even those providing direct on-the-job support. A differ- ence in the cost between the three job placement options is presented in Table 2.

\section{Qualitative Data}

Seventy-one individuals responded to the survey, with 35 (49.3\%) representing VR and 36 (50.7\%) from the CRP agencies. Of the VR respondents, $76.6 \%$ identified as a VR counselor working directly with the program, while $23.4 \%$ identified as the VR district supervisor. Of the CRP staff responding, 32.5\% were job developers, $46.0 \%$ were program supervisors, and $21.5 \%$ had another role within the program. Respondents were asked to rank the counselor attributes they believed contributed most to the successful outcomes of the participants, from most relevant to least relevant. Counseling and communication skills of the VR counselor with the participant was rated as the most significant to participant outcomes (35.2\%), followed by the VR counselor's collaboration skills with CRP providers (30\%). Communication was also mentioned among comments in "Other", along with client choice and acting with a sense of urgency.

In addition to the characteristics of the VR counselor, participants also ranked counseling and communication skills with the consumer as the most important characteristic of the job developer (46.3\%), followed by expertise of the staff in the area of disability. Comments in the "Other" section included references to the job developer's relationship with and understanding of the business community.

\section{Recommendations and Implications for Practice}

With data revealing a difference in outcomes across programs for individuals participating in ES and ESP versus SE services, the vocational rehabilitation agency might consider taking a closer look at the aspects of ESP that impact the successful outcomes of participants; they were related to a higher employment outcome and shorter duration of 
VR process, but required a higher cost of services. It is unclear if there are characteristics of ESP that could be incorporated into traditional SE to provide a more robust, individualized, and supportive job placement experience for the participant. The level of communication, collaboration, and the intensity of the support, combined with the specialized training available to all professional program staff, is perceived as a strong influencer of the current success of the program.

The VR agency might also consider whether other specific disability types would benefit from the same strategies employed by the ESP programs. This could involve research to create new ESP programs specific to other disability types. Or, it is possible the individual ESP programs could be expanded to include other disabilities, allowing participants to experience the additional supports that lead to success in employment.

Finally, there were several comments and suggestions included with the survey results in response to opportunities to provide additional information. The vocational rehabilitation agency would benefit from reviewing these openended comments with their management team to consider whether these suggestions should be incorporated into programs moving forward.

There are aspects of the Employment Services Plus program that may influence successful outcomes and warrant further study. Based on the current study results, the fol- lowing recommendations are offered based on lessons learned:

- Incorporate aspects of ESP that impact successful outcomes into all job placement programs.

- Provide training regarding communication and collaboration, and training in specialized disability areas, for employment service program staff and VR counselors.

- Explore whether other disability groups would benefit from ESP-specialized services.

\section{Author Note}

The contents of this paper were developed under a cooperative agreement with the U.S. Department of Education, Technical Assistance Center for Vocational Rehabilitation Agency Program Evaluation and Quality Assurance (PEQA-TAC) (Grant Award Number: H263B150004). However, the contents and views expressed in this publication do not necessarily represent the positions or policies of the U.S. Department of Education, and you should not assume endorsement by the Federal government. 


\section{References}

Missouri Vocational Rehabilitation. (2021). Community rehabilitation provider-vocational rehabilitation agreement. https://dese.mo.gov/media/pdf/crp-vr-agr eement
Wisdom, J., \& Creswell, J. W. (2013). Mixed methods: Integrating quantitative and qualitative data collection and analysis while studying patientcentered medical home models. Agency for Healthcare Research and Quality, 1-8. https://pcmh.ahrq.gov/site s/default/files/attachments/MixedMethods_032513co mp.pdf 